International Journal of Instruction e-ISSN: 1308-1470 • www.e-iji.net

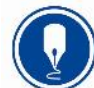

Article submission code: 20200622151755
Received: 22/06/2020

Revision: 23/12/2020
July $2021 \bullet$ Vol.14, No.3

p-ISSN: 1694-609X

pp. 393-416

Accepted: 17/01/2021

OnlineFirst: 22/05/2021

\title{
Learners' Mathematics Proficiency Levels on PISA 2018: A Comparative Study
}

\section{Refat Abdelsamad Abouelgheat Kandeel}

Assoc. Prof., King Saud University, Common First Year, Basic Sciences Department, Saudi Arabia, refat1011@yahoo.com

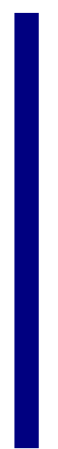

The study aimed to determine the levels of mathematics proficiency among Saudi learners and to compare them with the learners' levels of the first country globally (B-S-J-Z - China) and regionally (UAE) according to the results of PISA 2018, as well as to identify some of the learners' characteristics that affected their results and their mathematics proficiency levels. The results indicated low levels of mathematics proficiency among Saudi and Emirati learners, who are concentrated at levels 0 and 1 , as the levels of mathematics proficiency are very high among Chinese learners, who are concentrated at levels 5 and 6 . However, the levels of Emirati learners are slightly higher than Saudi learners, especially at levels 3, 4, and 5. The study also found some characteristics of learners that have the greatest impact on learners' results and levels of mathematics proficiency.

Keywords: achievement, mathematics, proficiency, PISA, international test

\section{INTRODUCTION}

The main goal of mathematics education is to teach not only routine mechanical procedures, but also the ideas, principles, generalizations, relationships, and skills to be used in situations outside the educational environment, and for completely different life purposes (Brownell, 2007) . There is an urgent need to not only learn mathematics, but to master it, due to the spread of information technology, the globalization of markets, and the skills required for the labor market. As the knowledge alone is not enough, as knowledge must be possessed with the ability to use it in appropriate situations; this is the main element of proficiency (Schoenfeld, 2007). Realizing that there is no mathematical term that includes all aspects of expertise, proficiency, knowledge, and facilities. The term "mathematics proficiency" has been chosen to express everything necessary for the successful learning of mathematics (NRC, 2001).

Mathematics proficiency is advanced mathematical knowledge and skills (Bartell et al., 2012), and the ability to engage in mathematics with understanding, computing, applying, reasoning, and engaging skills (Groves, 2012), while Kilpatrick, et al. (2001) defined it as knowledge, expertise, proficiency, and the facility of mathematics.

Citation: Kandeel, R. A. A. (2021). Learners' mathematics proficiency levels on Pisa 2018: A comparative study. International Journal of Instruction, 14(3), 393-416. https://doi.org/10.29333/iji.2021.14323a 
There are some previous studies that focused on the competence of mathematics learners and some factors affecting them, including Awofala (2017) study which found that elite high school learners have a high level of mathematics proficiency and that there are significant correlations between learner conceptual understanding, procedural fluency, strategic competence, adaptive thinking, productive behavior, and mathematics performance, and Dhlamini and Luneta (2016) study which indicated that learners were more efficient in analytic geometry questions that tested only procedural knowledge; the majority of learners were not adept at exam questions that measure conceptual knowledge in analytic geometry. This means that learners have left high school without being able to handle these subjects.

As Mahara, et al. (2015) confirmed that the website material which they designed to improve mathematics proficiency helped in removing common mathematical conflicts of some of our undergraduate mathematics learners. Also, it was found that nonmathematical terminology used could contribute to learners' mental conflicts, and AlMenoufy and Al-Mutham (2014) presented some classroom practices that can develop mathematics, and demonstrated the role of the educational community in doing so. In the same context the research-based Academy of MATH program is proven to be effective in helping learners acquire the fundamental math skills they need to achieve success in school and in their future careers, the program is designed to develop mathematics proficiency by addressing the major components of effective mathematics instruction (MacGregor, 2013). However, Ally (2011) reported that the promotion of mathematics proficiency in South African schools is weak and unstructured.

So many societies have been keen to participate in international tests that provide them with information about the achievement and proficiency of their learners in mathematics compared to other societies, such as the Trends in International Mathematics and Science Study (TIMMS) and the Program for International Learner Assessment (PISA) in fields of Reading, Mathematics, and Science. The Kingdom of Saudi Arabia has been keen to participate in TIMMS since 2009 and has also participated in PISA 2018. It has allotted huge budgets from the national income for these participations.

PISA assessments not only ascertain whether 15-year-old learners near the end of their compulsory education can reproduce what they have learned; they also examine how well learners can extrapolate from what they have learned and apply their knowledge in unfamiliar settings, both inside and outside of school. Learner performance in PISA is reported on a scale to help interpret what learners' scores mean in substantive terms. The scale is divided into levels of proficiency that indicate the kinds of tasks that learners whose scores are above a lower score limit are capable of completing successfully. The six proficiency levels used in the PISA 2018 mathematics assessment were the same as those established for the PISA 2003 and 2012 assessments, in which mathematics was the major area of assessment. The mathematical skills covered by the PISA test range from basic math principles (Level 0 below Level 1 - less than 358 points) to advanced thinking and reasoning skills and complex problem solving (Level 6 - greater than or equal to 669 points) (Organization for Economic Co-operation and Development (OECD), 2019). 
So some researchers have paid attention to the results of local and international mathematics tests, including the PISA and TIMSS tests, they are interested in studying the impact of some characteristics related to learners, teachers, school, home, and the environment on learner results, and they reached a set of results that may benefit many countries and societies in treating the shortcomings of their learners' performance and enhancing strengths. Some of these researchers have shown that the gender of the learner (male or female) has an impact on learners' results, with some of them pointing to the superiority of males' results in mathematics (Borghans \& Schils, 2011; Scherer \& Jens, 2014; Baye \& Monseur, 2016; Gray, et al., 2019) and others pointing to the superiority of females in previous PISA results (Wu, et al., 2019). However, Suh (2007) concluded that the learner's gender did not affect his or her results.

Some researchers indicated that the learners' characteristics affect their results in mathematics tests, these characteristics are: Learners' self-efficacy improves their results in mathematics tests (Borghans \& Schils, 2011; Thien, et al., 2015), learner personality traits greatly influence his results (Akyüz, 2014), when the learners are very disciplined and are not absent or late for their lessons, their results will be greatly improved (King, 2000; Roby, 2004), in general, the results of learners who enrolled in kindergarten are better than those who did not attend kindergarten (Blau \& Currie, 2006), the performance of learners who are highly motivated to participate in these tests is higher than that of other learners (Penk, et al., 2014), a learner who has knowledge of and is familiar with these tests will have improved performance (Burdett \& Sturman, 2013), a high socioeconomic level helps learners to perform better on various tests (Sirin, 2005; Caponera \& Losito, 2016), continuous parent, teacher, and school support for learners improves their performance levels on mathematics tests (Cai, 2003; Wilder, 2014; Pivovarova \& Powers, 2019), the learner's ability to read and interpret the questions of the test helps him to understand and solve these questions correctly (Koponen, et al., 2007; Kovas, et al., 2009; Mullis, et al., 2012), native country learners perform better than do immigrant learners on these tests (Dronkers, et al., 2014; Pivovarova \& Powers, 2019), training learners on similar models of these tests significantly improves their performance on the real tests (Hussain, et al., 2006; Khedr \& Desouki, 2014; Haelermans \& Ghysels, 2014), when a learner puts a lot of effort into testing, overcomes the stress he feels (Eklöf, Pavešič, \& Grønmo, 2014), and the learner who loves mathematics, and appreciates its importance to him and his community, his results are constantly improving (Lameva \& Chontiva, 2013).

Others indicated that some teachers' characteristics have an impact on the results of their learners, these characteristics are: Teacher training and professional development have a positive impact on their learners' performance on math tests (Goe, 2007; Skouras, 2012; Shannag, et al., 2013; Althauser, 2015; Zambak, et al., 2017; Mammadove \& Cimen, 2019), teachers' experience has an impact on learners' results as well, with learners performing better on math tests when their teachers have significant experience (Wayne \& Youngs, 2003; Odiembo \& Simatwa, 2014), learners' performance greatly improves when their teachers have higher qualifications (Goldhaber \& Brewer, 2000; Betts, et al., 2003), the evaluation practices that teachers use to assess the performance of their learners have a major impact on the performance of these 
learners on math tests (Mikk, 2006; Al-Bursan \& Tiegazza, 2012), teachers' discipline and their concern about not being absent or late for their learners' lessons help learners perform well on tests (King, 2000; Roby, 2004). Dee (2007), and Ismail (2008) pointed to the superiority of learners who have female teachers.

Other factors affect learners' results of math tests, such as educational curricula and methods (Hole et al., 2018), outlying values (Qwaider \& Al-Sawalmeh, 2016; Alatyan, 2018), parents' education level and qualifications (Kodippili, 2011; Azina \& Halimah, 2012), home atmosphere (Cooper, et al., 2000; Schweinhart, et al., 2005; Azina \& Halimah, 2012; Tucker-Drob \& Harden, 2012; Alonso, et al., 2016), school atmosphere (Akyüz, 2014; and homeworks (Abdelfattah \& Lam, 2018; Guven \& Akcay, 2019) .

In $2003, \mathrm{KSA}$ ranked $43^{\text {rd }}$ out of 45 countries with an average of 332 points at the eighth-grade level; the global average was 467 points. KSA ranked $46^{\text {th }}$ out of 49 countries in 2007, with an average of 329 at the eighth-grade level; the global average was 500 points and remains so today. In 2011 , KSA ranked $45^{\text {th }}$ out of 53 countries, with an average of 410 points at the fourth-grade level, and ranked $37^{\text {th }}$ out of 45 countries, with an average of 394 points at the eighth-grade level. Finally, in 2015, KSA ranked $46^{\text {th }}$ of the 49 participating countries, with an average of 383 points at the fourthgrade level, and 368 points at the eighth-grade level, where KSA ranked the last among 39 countries. In 2018, KSA took part in the PISA for the first time and ranked $73^{\text {rd }}$ out of 78 countries, with an average of 373 points in mathematics. The average of OECD countries was 489 points, and KSA ranked fifth in the Arab world out of six countries (United Arab Emirates (UAE), Qatar, Jordan, Lebanon, Saudi Arabia, and Morocco), with the UAE ranking the first regionally, with an average of 435 points. KSA overtook a single Arab country (Morocco). Beijing, Shanghai, Jiangsu, and Zhejiang (B-S-J-Z) provinces of China-ranked first globally, with an average of 591 points. This was B-SJ-Z's first participation in the PISA test, too.

\section{Research questions}

- RQ1. What are learners' mathematics proficiency levels in KSA compared to UAE and B-S-J-Z?

- RQ2. What are the characteristics of learners that affect their levels of mathematics proficiency in KSA compared to UAE and B-S-J-Z?

\section{METHOD}

KSA ranked low on first participation in PISA 2018. Therefore, the researcher conducted this study to determine the levels of mathematics proficiency among Saudi learners compared to Emirati and China (B-S-J-Z) learners, according to the results of PISA 2018. The study also sought to identify the impact of some learners' characteristics on these levels, to correct the path, treat weaknesses, and enhance learners' strengths, thereby improving their results in the future and enabling decisionmakers to develop their plans and strategies for developing learners' performance and improving their mathematics proficiency. 
The researcher used the descriptive methodology, which relies on analyzing and accurately describing data, to determine the levels of mathematical proficiency of the learners in the three countries, and he used the statistical package SPSS (T-test and ANOVA analysis) to determine the impact of learners' characteristics on their mathematics proficiency levels.

This study examined the PISA 2018 results from three countries (KSA, UAE, and B-SJ-Z). The sample of this study was 36,997 learners from three countries: KSA $(6,136)$, UAE $(18,864)$, and B-S-J-Z $(11,997)$. Not all learners answered all questions. The percentage of learners who answered questions ranging from $71.14 \%$ to $100 \%$.

Table 1

The sample

\begin{tabular}{llllclc}
\hline Country & KSA & \multicolumn{3}{c}{ UAE } & \multicolumn{3}{c}{ B-S-J-Z } \\
\hline The learners' grades & N & $\%$ & N & $\%$ & N & $\%$ \\
\hline The learners' gender & 6136 & $100 \%$ & 18864 & $100 \%$ & 11997 & $100 \%$ \\
\hline Mothers' qualifications & 6136 & $100 \%$ & 18864 & $100 \%$ & 11997 & $100 \%$ \\
\hline Fathers' qualifications & 6017 & $98.06 \%$ & 18746 & $99.37 \%$ & 11988 & $99.92 \%$ \\
\hline Place of birth & 5985 & $97.54 \%$ & 18679 & $99.02 \%$ & 11980 & $99.86 \%$ \\
\hline Home language & 5929 & $96.63 \%$ & 18452 & $97.82 \%$ & 11968 & $99.76 \%$ \\
\hline Age of starting kindergarten & 5365 & $71.14 \%$ & 15125 & $80.18 \%$ & 11064 & $92.22 \%$ \\
\hline Age of starting primary school & 6009 & $97.93 \%$ & 17385 & $92.16 \%$ & 11971 & $99.78 \%$ \\
\hline Learners' satisfaction & 5878 & $95.80 \%$ & 17467 & $92.59 \%$ & 11943 & $99.55 \%$ \\
\hline Learners' expectations & 5994 & $97.69 \%$ & 18008 & $95.46 \%$ & 11984 & $99.89 \%$ \\
\hline Learners' feeling & 5281 & $86.07 \%$ & 16557 & $87.77 \%$ & 11742 & $97.87 \%$ \\
\hline Parents' support & 5447 & $88.77 \%$ & 17348 & $91.96 \%$ & 11952 & $99.62 \%$ \\
\hline Learners' discipline & 5356 & $87.29 \%$ & 17193 & $91.14 \%$ & 11938 & $99.51 \%$ \\
\hline
\end{tabular}

FINDINGS

RQ1: To answer the first question, the numbers of learners and their percentages were calculated in each level of mathematics proficiency according to PISA 2018, as shown in table 2 which indicates that Saudi learners are the lowest in terms of mathematics proficiency compared to Emirati and Chinese learners, and the highest percentages of Saudi learners lie below the second level (Level 2), with a total of $70.89 \%$. The results of Emirati learners are almost the same, but the total percentage of learners below the second level is $47.74 \%$. Emirati learners are lower than Saudi learners at levels 0 and 1. Chinese learners constitute the highest percentages at 5, 4, and 6 levels of mathematics proficiency, with a total of $72.99 \%$. The percentage of Chinese learners at levels 0 and 1 is $(2.74 \%)$. 
Table 2

The percentages of learners in mathematics proficiency levels

\begin{tabular}{llllllll}
\hline Level & 0 & 1 & 2 & 3 & 4 & 5 & 6 \\
\hline Lower Score Limit & 0 & 358 & 420 & 482 & 545 & 607 & 669 \\
\hline KSA & 41.23 & 29.66 & 20.27 & 6.94 & 1.69 & 0.18 & 0.02 \\
\hline UAE & 25.30 & 22.44 & 21.74 & 16.55 & 9.11 & 3.77 & 1.09 \\
\hline B-S-J-Z & 0.56 & 2.18 & 7.17 & 17.10 & 27.52 & 27.81 & 17.66 \\
\hline
\end{tabular}

Figure (1) shows that Saudi and Emirati learners' percentages are concentrated at levels 0,1 , and 2, respectively, though the UAE has a lower percentage of learners at levels 0 and 1 , and there are percentages of Emirati learners in the top three levels (4, 5, and 6). The figure also shows that most Chinese learners are concentrated at the highest levels $(5,4,6$, and 3$)$, respectively, and there are few learners at the lowest levels $(0,1$, and 2$)$. In general, the results of Saudi learners are close to those of Emirati learners, and the results of Emirati learners are much better at levels 3, 4, and 5. However, the results of Chinese learners are the highest and are concentrated at the highest levels of mathematics proficiency.

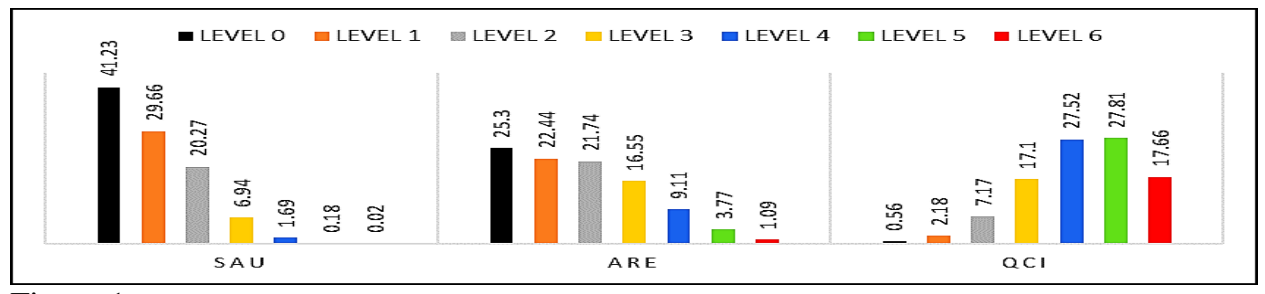

Figure 1

The percentages of learners at the levels of mathematics proficiency

RQ2: To answer this question, the researcher identified some learners' characteristics affecting their levels of mathematics proficiency by reviewing the literature and previous studies, as well as the PISA learner questionnaire, namely: learners' grades, learners' gender, mothers' qualifications (the researcher adopted the highest qualification), fathers' qualifications (the researcher adopted the highest qualification), the age of starting kindergarten (ISCED 0), the age of starting primary school (ISCED 1), learners' satisfaction with their lives (learners were divided into four categories very low (less than 2.5 out of 10), low (2.5 - 5), high (5 - 7.5), and very high (7.5-10)), place of birth, home language (learners were divided into two categories (as a test language, different language)), education level that the learner expects to achieve, learners' feeling comfortable (Happy, Lively, Proud, Joyful, and Cheerful) or uncomfortable (Scared, Miserable, Afraid, and Sad), parents' support-learners were divided into four categories (very strong, strong, poor, and very poor support), and learners' discipline. Then the researcher used a T-test and ANOVA analysis to determine the impact of these characteristics on learners' mathematics proficiency levels in KSA compared to the $\mathrm{UAE}$ and B-S-J-Z. The percentages of learners were calculated according to the learners' categories at each of the mathematics proficiency levels, as shown in the following: 
Learners' grades: An ANOVA analysis, and follow-up Scheffe and Tamhane tests revealed that in the three countries, there are statistically significant differences between the different groups of learners in favor of the learners in grades 10, 11, and 12 compared to the learners in grades 7, 8, and 9 (KSA: F $(5,6130=104.72, \mathrm{p}<0.05)$; UAE: F $(5,18858=350.70, \mathrm{p}<0.05)$; B-S-J-Z: F $(5,11991=88.27, \mathrm{p}<0.05))$. The averages of Saudi learners reached 385.38, 385.44, and 410.04 in the three upper grades, respectively, 424.78, 461.70, and 525.92 in UAE, and 600.84, 605.15, and 610.30 in B-S-J-Z. The seventh grade had the worst results in the three countries, with averages of 288.87 in KSA, 324.20 in UAE, and 492.13 in B-S-J-Z.

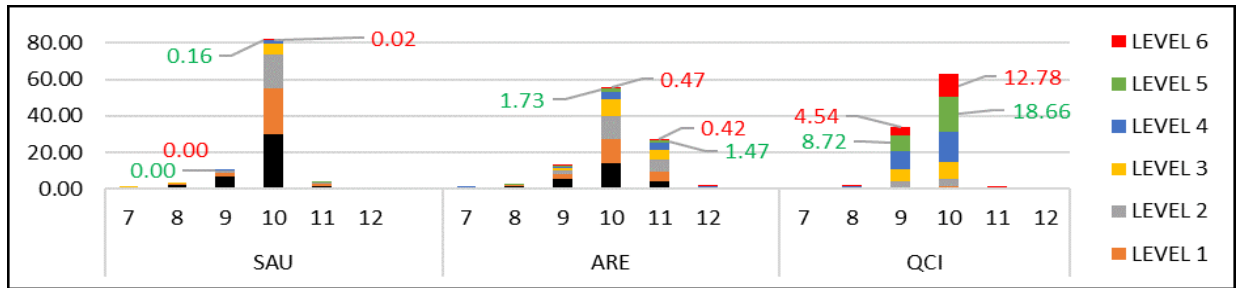

Figure 2

The percentages of learners according to their grades

It is clear from the previous figure that Saudi learners are concentrated in the $10^{\text {th }}$ grade, and Emirati learners are concentrated in the $10^{\text {th }}$ and $11^{\text {th }}$ grades, as Chinese learners are concentrated in the $10^{\text {th }}$ and $9^{\text {th }}$ grades. The percentages of Chinese learners at levels 4 , 5, and 6 of mathematics proficiency are more than those of Saudi and Emirati learners. There are very low percentages of learners at these three top levels in the UAE, while Saudi learners at levels 5 and 6 are almost non-existent.

Learners' gender: The following table indicates that there are statistically significant differences between the averages of learners in favor of Saudi and Emirati female learners, whose averages reached 384.05 and 435.85, respectively. Meanwhile, the averages of male learners reached 369.73 and 423.69. In B-S-J-Z, the differences between the averages of learners were in favor of male learners, whose average was 596.17, while the average of female learners was 588.35.

Table 3

T-score and statistical significance according to the learners' gender

\begin{tabular}{lllllll}
\hline Country & Gender & $\mathrm{N}$ & Mean & SEM & T-Score & \multirow{2}{*}{ Sig. } \\
\hline \multirow{2}{*}{ KSA } & Female & 2992 & 384.05 & 1.36 & \multirow{2}{*}{7.12} & \multirow{2}{*}{000} \\
& Male & 3144 & 369.73 & 1.48 & \\
\hline \multirow{2}{*}{ UAE } & Female & 9380 & 435.85 & 0.97 & \multirow{2}{*}{8.20} & \multirow{2}{*}{000} \\
& Male & 9897 & 423.69 & 1.11 & & \multirow{2}{*}{.000 } \\
\multirow{2}{*}{ B-S-J-Z } & Female & 5775 & 588.35 & 1.05 & \multirow{2}{*}{-5.15} & \\
& Male & 6283 & 596.17 & 1.09 & & \\
\hline
\end{tabular}

The following Figure indicates that male learners are more than female learners at the highest levels of mathematics proficiency in the three countries, with $24.94 \%$ of Chinese male learners at the highest levels (5 and 6) of mathematics proficiency as compared to 
$20.54 \%$ of female learners. In KSA, $0.12 \%$ of male learners and $0.08 \%$ of female learners are at the same levels, while in the UAE, 3.05\% of male learners and $1.81 \%$ of female learners are at the same levels. The differences in these results are due to the high numbers of female learners at levels 1 and 2 of mathematics proficiency in KSA, and at levels 1,2 , and 3 in UAE.

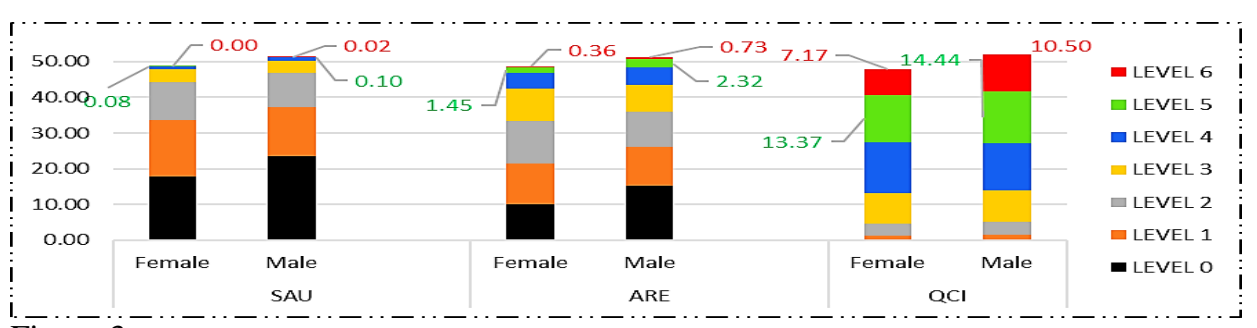

Figure 3

The percentages of learners according to their gender.

Mothers' qualifications (MQ): F-score, statistical significance, and post hoc tests indicate statistically significant differences between the averages of learners in favor of learners whose mothers obtained level (ISCED 5A) compared to other learners in the three countries $($ KSA: $\mathrm{F}(8,6008=45.15, \mathrm{p}<0.05)$; UAE: $\mathrm{F}(8,18737=182.32$, $\mathrm{p}<$ $0.05)$; B-S-J-Z: F $(8,11979=121.92, \mathrm{p}<0.05))$, with the averages of learners being $395.87,475.92$, and 630.37, respectively.

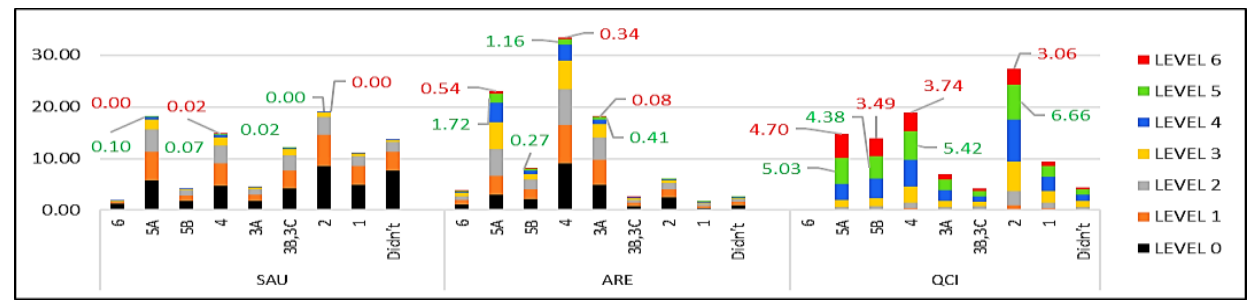

Figure 4

The percentages of learners according to their mothers' qualifications

Figure (4) shows that most of the mothers' qualifications in KSA are (ISCED 2, ISCED 5A, ISCED 4, or didn't complete ISCED 1). In the UAE, they are (ISCED 4, ISCED 5A, or ISCED 3A), while in B-S-J-Z they are (ISCED 2, ISCED 4, ISCED 5A, or ISCED 5B). The figure also shows that Saudi learners whose mothers obtained level (ISCED 4) achieved level 5 and 6 of mathematics proficiency. Emirati learners whose mothers obtained level (ISCED 5A or ISCED 4) achieved the same levels, while Chinese learners whose mothers obtained level (ISCED 5A, ISCED 4, ISCED 5b, or ISCED 2) achieved the same level. However, Chinese learners are more than Saudi and Emirati learners, as well as Emirati learners are more than Saudi learners. The learners whose mothers obtained level (ISCED 6) did not get high points in this PISA test in the three countries. 
Fathers' qualifications (FQ): There are statistically significant differences between the averages of learners in favor of the averages of learners whose fathers obtained level (ISCED 5A) compared to the other learners in B-S-J-Z and UAE, as well as compared to the learners whose fathers obtained level (ISCED 6, ISCED 2, ISCED 3B, 3C, and ISCED 3A) in KSA, (KSA: F (8, $5976=43.08, p<0.05)$; UAE: F $(8,18670=197.68$, $\mathrm{p}<0.05)$; B-S-J-Z: F $(8,11971=143.97, \mathrm{p}<0.05))$, where the averages of these learners whose fathers obtained level (ISCED 5A) in KSA, UAE, and B-S-J-Z are $393.45,475.97$, and 634.14, respectively.

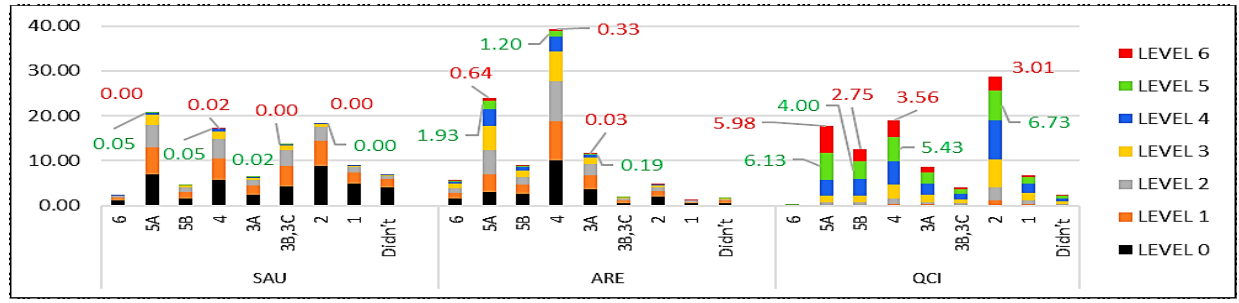

Figure 5

The percentages of learners according to their fathers' qualifications

Figure (5) shows that the top qualifications among fathers were (ISCED 5A, ISCED 2, and ISCED 4), respectively, in KSA. They were (ISCED 4 and ISCED 5A) in the UAE, and (ISCED 2, ISCED 4, and ISCED 5A) in B-S-J-Z. The figure also shows that the highest levels of mathematics proficiency ( 5 and 6 ) were achieved by few Saudi learners whose fathers obtained level (ISCED 4). In the UAE, learners whose fathers obtained level (ISCED 5A or ISCED 4) achieved level 5 and 6 of mathematics proficiency, with more learners than KSA, but still less than B-S-J-Z. Chinese learners whose fathers obtained level (ISCED 5, ISCED 4, or ISCED 2) achieved level 5 and 6 . The figure also shows that the learners whose fathers obtained level (ISCED 6) did not get high points in this PISA test in the three countries.

The age of starting kindergarten (ISCED 0): Through F-score and statistical significance (KSA: F $(6,4358=32.75, \mathrm{p}<0.05)$; UAE: F $(6,15118=145.89, \mathrm{p}<$ $0.05)$; B-S-J-Z: F $(6,11057=116.15, \mathrm{p}<0.05))$, it is clear that there are statistically significant differences between the different groups of learners in the three countries, related to the age at which the learners started kindergarten (ISCED 0). The post hoc tests revealed that these differences were in favor of the averages of learners $(380.14$ and 406.63) who started kindergarten at the ages of 2 and 3 years compared to the averages of learners (351.58 and 372.53) who started kindergarten at the ages of 1 and 6 years in KSA. In UAE, the differences were in favor of the averages of learners (461.94 and 443.29) who started kindergarten at the ages of 3 and 4 years, compared to the averages of other learners. In B-S-J-Z, the differences were in favor of the averages of learners (616.95 and 608.67) who started kindergarten at the ages of 2 and 3 years, compared to the averages of other learners. 


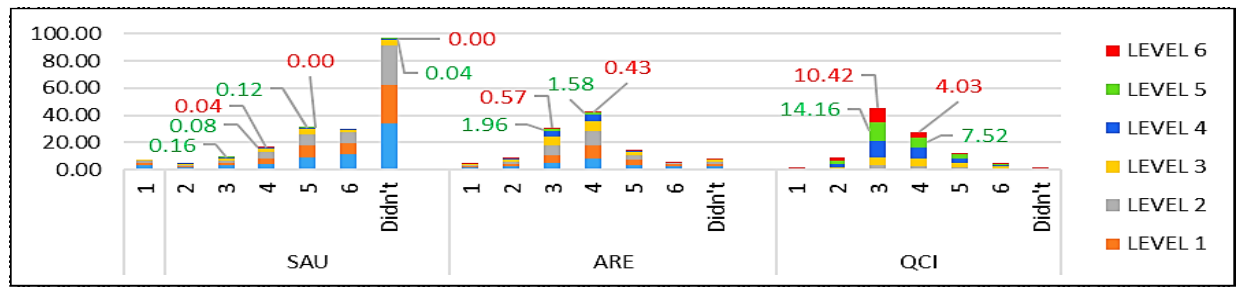

Figure 6

The percentages of learners according to their age upon starting kindergarten

Figure (6) indicates that there is an increase in Saudi learners who did not enroll in kindergarten, and an increase in Emirati and Chinese learners who started kindergarten at the ages of 3 and 4 . It also indicates that the percentages of Chinese learners in levels 5 and 6 of mathematics proficiency are more than the percentages of Saudi and Emirati learners. The UAE has lower numbers of learners at these levels, and these numbers are almost non-existent in KSA, as the figure confirms that the learners who started kindergarten at the ages of 3 or 4 obtained more points than did others in the three countries. In KSA, the learners who started kindergarten at the age of 3 have the highest percentage $(0.16 \%)$ at level 5 of mathematics proficiency, while learners who started kindergarten at the age of 4 have the highest percentage of learners $(0.04 \%)$ at level 6 . These results are almost the same in the UAE and B-S-J-Z, but the percentages are slightly higher in the UAE and are the highest in B-S-J-Z.

The age of starting primary school (ISCED 1): The aforementioned ANOVA analysis-(KSA: F $(4,6004=32.75, \mathrm{p}<0.05)$; UAE: F $(5,17379=171.65, \mathrm{p}<0.05)$; B-S-J-Z: F $(5,11965=157.01, \mathrm{p}<0.05)$ ) - and follow-up tests showed that Saudi learners who started (ISCED 1) at the age of 6 years scored significantly higher (379.54) than those who started primary school (ISCED 1) at the ages of 8 and 9 years (350.70 and 303.43). Emirati learners who started (ISCED 1) at the ages of 4, 5, and 6 years scored significantly higher $(425.02,458.03$, and 438.02) than those who started (ISCED 1) at the ages of 7, 8, and 9 years $(409.82$, 396.13, and 334.19), while Chinese learners who started (ISCED 1) at the ages of 5, 6, and 7 years scored significantly higher $(601.04,613.16$, and 584.25) than those who started (ISCED 1) at the ages of 4,8 , and 9 years $(509.59,530.96$, and 518.53$)$.

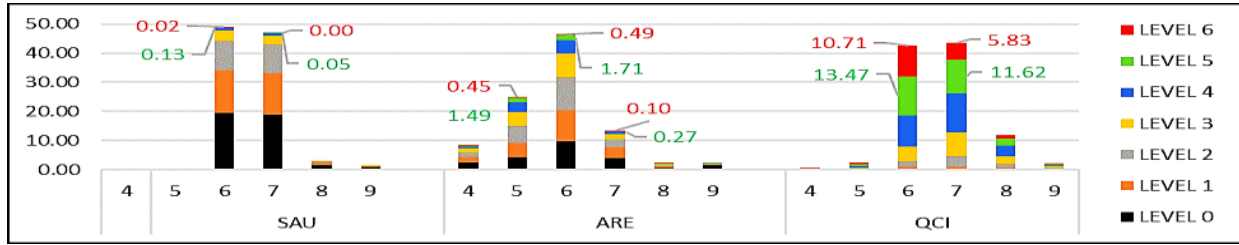

Figure 7

The percentages of learners according to their age of enrollment in primary school

Figure (7) shows the enlarged numbers of learners who started (ISCED 1) at the ages of 6 and 7 in KSA and B-S-J-Z, and at the ages of 5 and 6 in the UAE. It also shows the 
high percentages of Chinese learners at levels 5 and 6 in terms of mathematics proficiency. The UAE has very low percentages of learners at these levels, but these percentages are still higher than the percentages of Saudi learners. The learners who started (ISCED 1) at the age of 6 were the highest in the three countries, at levels 5 and 6 of mathematics proficiency. In addition, Emirati learners at levels 3 and 4 of mathematics proficiency were greater in number than Saudi learners.

Learners' satisfaction with their lives: The usual analysis- $-(\mathrm{KSA}: \mathrm{F}(3,5874=8.71$, $\mathrm{p}<0.05)$; UAE: F $(3,17463=65.66, \mathrm{p}<0.05)$; B-S-J-Z: F $(3,11939=18.77, \mathrm{p}<$ $0.05)$ ) - and follow-up tests determined that in the three countries, learners who are highly satisfied with lives scored significantly higher $(385.30,458.82$, and 601.97) than all other learners in UAE and B-S-J-Z, and the learners who have very high satisfaction with their lives in KSA.

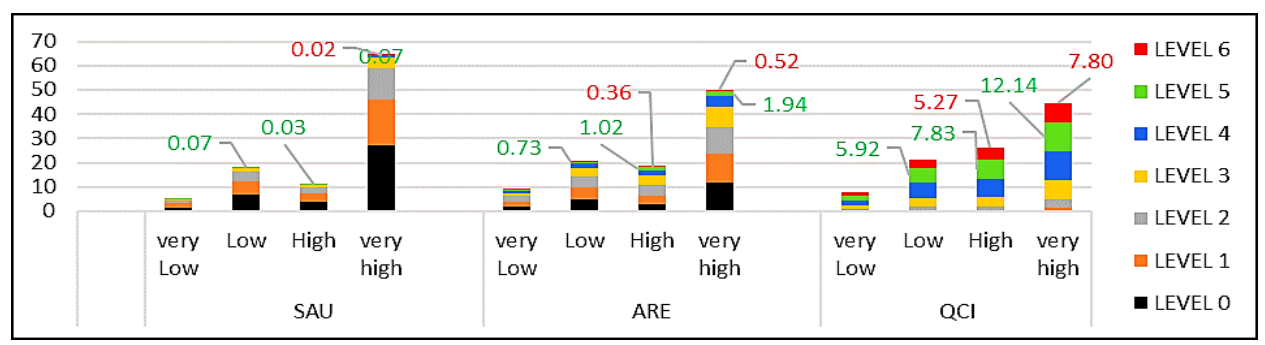

Figure 8

The percentages of learners according to their satisfaction with their lives

Figure (8) shows that the largest number of learners have very high satisfaction with their lives in the three countries. Saudi learners have the largest percentage at this level, followed by Emirati learners and then Chinese learners. The figure also shows that the highest levels of mathematics proficiency ( 5 and 6 ) have been achieved by learners who have high satisfaction with their lives in the three countries, though Emirati learners at these levels of mathematics proficiency (5 and 6) are more than Saudi learners; Saudi learners are very few at the same levels. The figure also shows that Emirati learners at levels 3 and 4 of mathematics proficiency are more than Saudi learners.

Learners' place of birth: The T-score and statistical significance in table (4) indicate that there are statistically significant differences between the averages of learners in favor of learners who were born in another country (Immigrants) in KSA and UAE, where the averages of these learners were 414.29 and 476.69, respectively. Meanwhile, the averages of learners who were born in KSA and UAE (Native) were 376.30 and 409.19. In B-S-J-Z, the learners who were born in B-S-J-Z scored significantly higher compared to those who were born in another country. 
Table 4

T-score and statistical significance according to place of birth

\begin{tabular}{lllllll}
\hline Country & PB & NO & Mean & SEM & T-Score & Sig. \\
\hline \multirow{2}{*}{ KSA } & Native & 5560 & 376.30 & 1.04 & -9.052 & \multirow{2}{*}{000} \\
& Immigrants & 369 & 414.29 & 4.22 & & \multirow{2}{*}{000} \\
\hline \multirow{2}{*}{ UAE } & Native & 12350 & 409.19 & 0.87 & -43.984 & \multirow{2}{*}{000} \\
& Immigrants & 6102 & 476.69 & 1.29 & & \multirow{2}{*}{ B-S-J-Z } \\
& Native & 11901 & 593.05 & 0.76 & \multirow{2}{*}{1.454} & \\
& Immigrants & 67 & 578.25 & 16.56 & & \\
\hline
\end{tabular}

Figure (9) shows that most of the learners who took part in the PISA test 2018 were native, and the learners who were born in B-S-J-Z and KSA (Native) represent the largest percentage of learners at levels 5 and 6 of mathematics proficiency, respectively. There were very few learners in KSA, while Emirati learners who were born in another country (Immigrants) represent the largest percentage at levels 6 and 5 of mathematics proficiency. This figure shows that Emirati learners (Native and Immigrants) at level 4 of mathematics proficiency are more than Saudi learners at the same level.

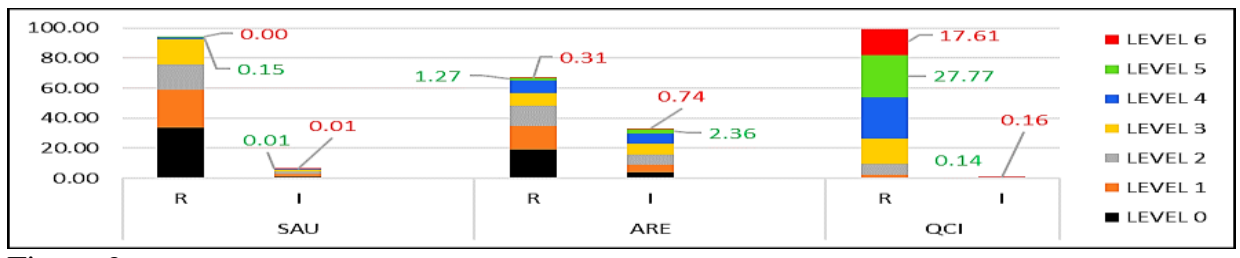

Figure 9

The percentages of learners according to their place of birth

Learners' language in their homes: The following table indicates that Saudi and Chinese learners who used the PISA test language in their homes scored significantly higher than did those who used a different language; the averages of these learners were 378.15 and 593.13, respectively, while the averages of other learners were 363.67 and 512.54. The table also indicates that Emirati learners who used a different language scored significantly (458.38) higher compared to others (411.60).

Table 5

T-score and statistical significance according to home language (As the test, Different)

\begin{tabular}{|c|c|c|c|c|c|c|}
\hline Country & HL & NO & Mean & SEM & T-Score & Sig. \\
\hline \multirow{2}{*}{ KSA } & As the test & 5568 & 378.15 & 1.05 & \multirow{2}{*}{3.305} & \multirow{2}{*}{0.012} \\
\hline & Different & 346 & 363.67 & 4.63 & & \\
\hline \multirow{2}{*}{ UAE } & As the test & 10888 & 411.60 & 0.98 & \multirow{2}{*}{-31.310} & \multirow{2}{*}{0.006} \\
\hline & Different & 7780 & 458.38 & 1.12 & & \\
\hline \multirow{2}{*}{ B-S-J-Z } & As the test & 11934 & 593.13 & 0.76 & \multirow{2}{*}{7.367} & \multirow{2}{*}{0.245} \\
\hline & Different & 58 & 512.54 & 12.39 & & \\
\hline
\end{tabular}

Through figure (10), it is clear that most of the learners who took part in the PISA test 2018 were using the test language in their homes. However, the percentages of learners 
(who were using the test language and who were using another language) are very close in UAE only. The figure also shows that learners who were using the test language in their homes are more than others at levels 5 and 6 in terms of mathematics proficiency in B-S-J-Z and KSA, respectively, though these numbers are very low in KSA. In the UAE, learners who were using a different language in their homes were more than others at the same levels of mathematics proficiency. Emirati learners at levels 3 and 4 of mathematics proficiency are more than Saudi learners at the same levels.

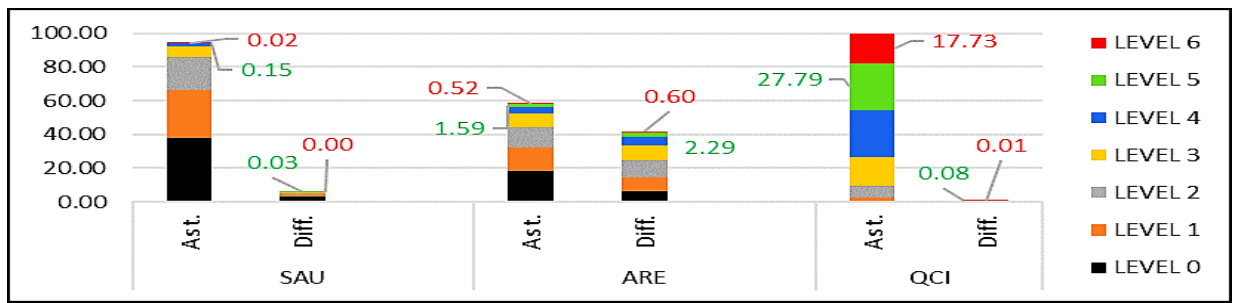

Figure 10

The percentages of learners according to the language in their homes

Learners' feeling comfortable or uncomfortable: According to the F-score and statistical significance (KSA: F $(2,5278=48.34$, p < 0.05); UAE: F $(3,16553=0.13$, $\mathrm{p}<0.05)$; B-S-J-Z: F $(3,11738=6.49, \mathrm{p}<0.05))$ and post hoc tests, there are statistically significant differences between the averages of learners in the three countries due to their feeling comfortable (Happy, Lively, Proud, Joyful, and Cheerful) or uncomfortable (Scared, Miserable, Afraid, and Sad) in favor of the average of Saudi learners (389.23) who always feel comfortable compared to the averages of other learners, and in favor of the averages of Chinese learners (595.94 and 593.37) who always and sometimes feel comfortable. Meanwhile, there are no statistically significant differences between the averages of Emirati learners due to their feelings.

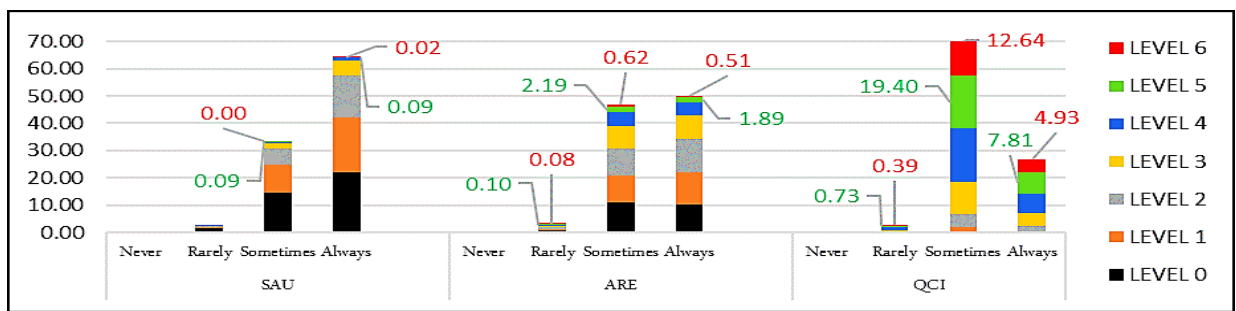

Figure 11

The percentages of learners according to their feeling comfortable or uncomfortable

The previous figure indicates that the largest number of learners in the three countries always or sometimes feel comfortable. The largest number of Saudi learners always feel comfortable, followed by Emirati learners, then Chinese learners. The largest number of Chinese learners sometimes feel comfortable. The figure also shows that some learners who always or sometimes feel comfortable achieved level 5 and 6 of mathematics proficiency; these numbers are very few in UAE, almost non-existent in KSA, and many 
in B-S-J-Z. In addition, the numbers of Emirati learners at levels 3 and 4 of mathematics proficiency are more than Saudi learners at the same levels.

Learners' expectation of their education level: The results of ANOVA analysis(KSA: F $(5,5988=126.50, \mathrm{p}<0.05)$; UAE: F $(5,18002=377.82, \mathrm{p}<0.05)$; B-S-J-Z: $\mathrm{F}(5,11978=938.58, \mathrm{p}<0.05))$-indicates that there are statistically significant differences between the averages of learners in the three countries due to the level of education that the learners expect to achieve, in favor of the averages of learners $(392.09,450.29$, and 623.72) who expect to achieve level (ISCED 5A or 6) in the three countries compared to the averages of other learners.

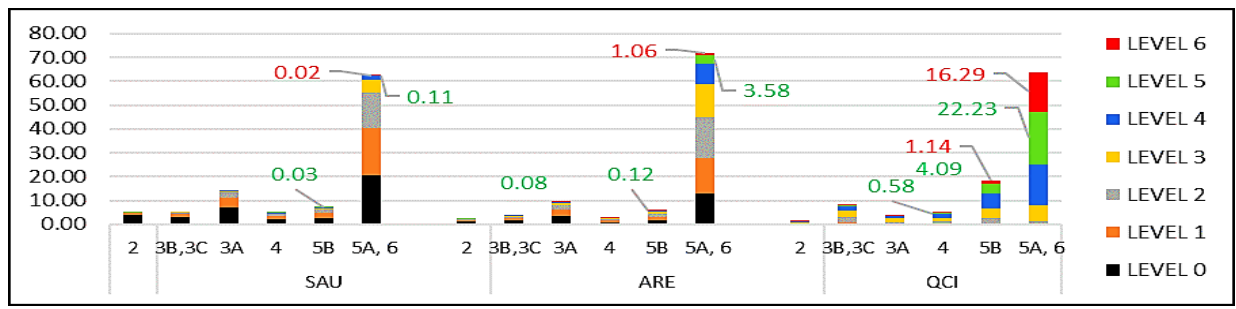

Figure 12

The percentages of learners according to their expectation of their education level

Figure (12) shows that level (ISCED 5A or 6) is the educational level that most learners expect to achieve in the three countries, and the highest levels of mathematics proficiency ( 5 and 6 ) have been achieved by learners who expect the highest education level (ISCED 5A or 6) in the three countries. However, the percentages of learners at levels 5 and 6 is very few (4.64\%) in the UAE compared to China (38.51\%), though the UAE percentage is greater than the percentage of Saudi learners $(0.13 \%)$.

Parents' support for their children: The results of the analysis- $($ KSA: F $(3,5443=$ 136.29, $\mathrm{p}<0.05)$; UAE: F $(3,17344=270.69, \mathrm{p}<0.05)$; B-S-J-Z: F $(3,11948=$ $134.73, \mathrm{p}<0.05)$ ) - indicate that learners who received very strong parental support in KSA, UAE, and B-S-J-Z scored significantly higher than others, with the averages of these learners being $396.31,452.45$, and 607.58 , respectively. The points' average of Chinese learners is the largest, followed by the points' average of Emirati learners, and then the points' average of Saudi learners.

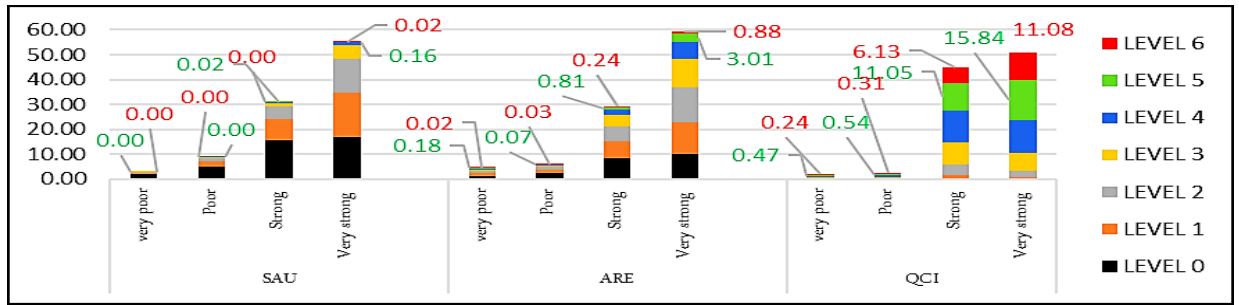

Figure 13

The percentages of learners according to their parents' support 
Figure (13) shows that the largest number of learners in the three countries received very strong support from their parents, then strong support. However, the percentage of these learners in B-S-J-Z is greater than the percentage of the same learners in KSA and UAE. The figure also shows that the highest levels of mathematics proficiency ( 5 and 6 ) were achieved by learners who received very strong parental support in the three countries, though the percentage of these learners at level 5 in UAE (3.01\%) is greater than the percentage of Saudi learners $(0.16 \%)$ at the same level. Meanwhile, Emirati learners at levels 3 and 4 are more than Saudi learners at the same levels.

Learners' discipline: The usual analysis - $(\mathrm{KSA}: \mathrm{F}(3,5352=14.87, \mathrm{p}<0.05)$; UAE: $\mathrm{F}(3,17189=185.75, \mathrm{p}<0.05)$; B-S-J-Z: F $(3,11934=69.75, \mathrm{p}<0.05))$ - and followup tests show that the averages of learners who have very high or high discipline in their schools were significantly higher (UAE: 439.84 and 448.84; B-S-J-Z: 582.48 and $599.01)$ than those who have low or very low discipline, though Saudi learners who have high discipline scored significantly (385.04) higher than other Saudi learners.

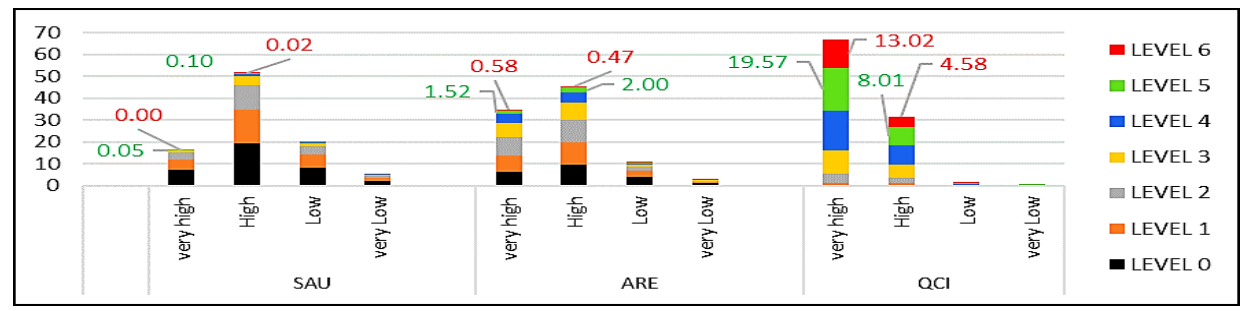

Figure 14

The percentages of learners according to their discipline

Figure (14) shows that the largest number of learners in KSA and UAE have high discipline in their schools, while the largest number of learners have very high discipline in B-S-J-Z. The figure confirms that the highest levels of mathematics proficiency (5 and 6) have been achieved by learners who have high or very high discipline in the three countries. These learners are few in ARE, but they are more than the Saudi learners at the same levels, as the numbers of Emirati learners at levels 3 and 4 of mathematics proficiency are more than the numbers of Saudi learners.

\section{DISCUSSION AND RECOMMENDATIONS}

The results of this study indicate the superiority of Chinese learners at levels 4, 5 and 6 of mathematics proficiency in the PISA test 2018 over Emirati and Saudi learners, as well as the low results of Saudi learners as compared to Emirati learners at levels 3, 4, and 5 of mathematics proficiency. Saudi learners at level 0 of mathematics proficiency are much greater than Emirati and Chinese learners at the same level. Therefore, Saudi learners have a big problem in terms of mathematics proficiency. It is necessary to pay more attention to teaching and learning mathematics in modern and advanced ways from childhood to develop learners' mathematics proficiency levels and to train learners in taking international mathematics tests such as the PISA test. Hussain, et al., (2006), Khedr and Desouki (2014), and Haelermans and Ghysels (2014) emphasized the importance of training learners to take mathematics tests to improve their performance. 
Al-Sheikhi (2012) also stressed that teachers should use new strategies to improve learners' performance.

Additionally, the results indicate some of the learners' characteristics that affected their mathematics proficiency levels, according to the PISA 2018 test. The results indicated that the averages of learners in grades 10,11, and 12 are better than the averages of other learners in grades 7, 8, and 9, and their levels of mathematics proficiency are high. Learners in grade 12 achieved the best results in the three countries (KSA, UAE, and BS-J-Z), followed by learners in grade 11, then learners in grade 10. Thus, if possible, officials and experts should focus on this group of learners when selecting the sample of learners who will take part in international tests such as the PISA test. They also must move away from learners in lower grades, especially grade 7, whose results were the worst in the three countries. Female learners scored significantly higher than male learners in KSA and UAE, which is consistent with the study of Wu et al. (2019), while male learners are the best in B-S-J-Z. This result confirms what Borghans and Schils (2011), Scherer and Jens (2014), Baye and Monseur (2016), and Gray et al. (2019) indicated in their studies, though they differ from Suh's (2007) finding that there are no differences between male and female learners in terms of performance. The results also show a marked superiority of male learners at levels 5 and 6 of mathematics proficiency in the three countries. Thus, officials and experts should focus on educating male learners about the importance of these tests, training them continuously and increasing attention paid to female learners so that their results improve in general and their mathematics proficiency levels rise, as most of them achieved the medium levels of mathematics proficiency. The mathematics proficiency levels of learners whose parents obtained a high level (ISCED 5A) are better than others on the PISA test 2018. Cai (2003), Wilder (2014), and Pivovarova and Powers (2019) stressed the importance of the parents' support in improving the performance of their children and raising their levels of mathematics proficiency. Thus, the countries that seek to improve the performance of their learners on the PISA tests such as KSA, UAE, and others, should choose learners whose parents have high qualifications and increase the awareness of parents who do not have these qualifications or who have low qualifications to care for their children and motivate them to improve their performance on international mathematics tests.

The results show that learners who started kindergarten (ISCED 0) at the age of 3 or 4 achieve better results than others, and their mathematics proficiency levels are high. Thus, it is preferable to enroll children in kindergarten at the age of 3 or 4 at most, in order to achieve good results on international math tests such as the PISA test, as well as to improve mathematics proficiency levels. The results also indicate that a very high number of Saudi learners did not enroll in kindergarten, which is perhaps the main reason for the learners' low level of mathematics proficiency. On the other hand, Emirati and Chinese learners typically enrolled in kindergarten at the age of 3 or 4 , which had a major impact on improving their mathematics proficiency levels. This result is very consistent with the findings of Blau and Currie (2006), who indicated that enrolling learners in kindergarten greatly improves the results of learners. The results also 
indicated that the best age for starting primary school is 6 , as learners who start primary school at this age achieve high mathematics proficiency levels. Therefore, to achieve high mathematics proficiency levels, learners must enroll in primary school at the age of 6 and not after that. The results also show that a very large number of Saudi learners enrolled in primary school at the age of 7 , which may have had a significant impact on the learners' results in the PISA 2018, as well as on their mathematics proficiency levels. The study found that a high level of learners' satisfaction with their lives improves their mathematics proficiency levels, though Saudi learners have a low level of mathematics proficiency despite their high level of satisfaction with their lives as compared to Emirati and Chinese learners. The performance of Emirati and Chinese learners on the PISA 2018, and their mathematics proficiency levels, are more than those of Saudi learners. Perhaps if Chinese learners were more satisfied with their lives, their mathematics proficiency would have increased even more. Such results would be consistent with the results of Sirin (2005) and Caponera and Losito (2016), who indicated that a high socioeconomic level helps learners perform better on mathematics tests, as a high socioeconomic level increases learners' satisfaction with their lives. The study found that native learners who were born in the same country in which they had taken the test scored significantly higher than immigrant learners who were born in another country. They also had higher mathematics proficiency levels. Therefore, only learners who were born within the country should be allowed to participate in international math tests, in order to improve their results and their mathematics proficiency levels (Dronkers, et al., 2014; Pivovarova \& Powers, 2019). Immigrant learners do not care as much about the results of these tests, as the results do not affect them or their country. The results also confirmed that learners who speak the test language in their homes scored significantly higher than did learners who speak another language in their homes, and they achieved high mathematics proficiency levels (5 and 6 ), especially Chinese learners. This result is partly consistent with the findings of Koponen, et al. (2007), Kovas, et al. (2009), and Mullis, et al., (2012), who confirmed that the learner's ability to read and interpret the questions of the test helps him understand and answer these questions correctly. Therefore, parents should pay attention to the language they speak at home so that they conform to the language of the international tests in which the learners will participate. They should constantly be aware of this in order to improve the results and mathematics proficiency levels of their children in international tests such as the PISA test.

The results of this study also confirmed the superiority of learners who expect a higher level of education (ISCED 5A or 6) over others in terms of results and mathematics proficiency levels. Where the learners' expectations increase, their results and mathematics proficiency levels will improve. Therefore, countries -especially KSAshould focus on raising the level of their learners' expectations, and also urge parents to pay attention to this matter, so that learners' results and mathematics proficiency levels improve on these international tests. This result is partly consistent with the results of Jeynes (2005), who concluded that parents' promotion of their children's academic aspirations, and high expectations of parents for their children's future, enhance their children's levels and improve their performance. This study revealed the importance of 
increasing parental support for learners, which is represented by parental support for learners' efforts and educational achievements, support for learners when they face difficulties in school, and the encouragement of learners to have self-confidence. An increase in this support will improve the results of learners, and their mathematics proficiency levels will improve. Therefore, parents -especially in KSA- must constantly increase parental support in order to improve the performance and mathematics proficiency levels of their children. This result confirms what Cai (2003), Wilder (2014), and Pivovarova, and Powers (2019) emphasized: that continued parent, teacher, and school support for learners improves their performance levels on the mathematics tests. As this study's results showed, the learners' feelings in terms of being comfortable (Happy, Lively, Proud, Joyful, and Cheerful) or uncomfortable (Scared, Miserable, Afraid, and Sad) affected their results on the PISA test. The results of this study emphasized the importance of learners' feeling comfortable in order to achieve positive and high results. Learners who always or sometimes felt comfortable achieved high results, and some of them achieved high levels of mathematics proficiency. The results of learners who did not feel comfortable were low, and very few of them achieved high mathematics proficiency levels $(4,5$, and 6$)$ in the three countries. So, learners must continuously feel comfortable in order to achieve good results on international tests. Parents assume this role in achieving the target, followed by the school and teachers. This result is related in one way or another to learners' socioeconomic level and satisfaction with their lives. The results of the current study indicated that the discipline of learners in their schools, as represented by absences and skipped lessons and days, affects learners' performance and results on math tests. Highly disciplined learners scored significantly higher than those who had no or low discipline, and they achieved high levels of mathematics proficiency. This result reinforces the results of King (2000) and Roby (2004), who indicated that the results of learners who are very disciplined and are not absent or late for their lessons will be greatly improved. The results of this study confirm the importance of school discipline in improving learners' results and levels of mathematics proficiency. Therefore, the school, teachers, and parents should urge learners to be disciplined and educate them about its importance in achieving their goals.

\section{CONCLUSION}

From the foregoing, the results indicated low levels of mathematics proficiency among Saudi and Emirati learners, they are concentrated at levels 0 and 1, as the levels of mathematics proficiency are very high among Chinese learners, who are concentrated at levels 5 and 6. However, the levels of Emirati learners are slightly higher than Saudi learners, especially at levels 3,4 , and 5 . The study also found some characteristics of learners led, or may lead, to high results and high levels of mathematics proficiency. These characteristics are: focusing on learners in grades 10, 11, and 12 and constantly training them on international tests such as the PISA test, focusing on male learners without neglecting female learners and their training in high levels of mathematics proficiency, educating parents and qualifying them with appropriate training from childhood so that they can help their children in the near future, enrolling children in kindergarten at the age of 3 or 4 to improve their results in the future, and enrolling them 
in primary school at the age of 6 , and not after that, as this is the best age to achieve good results and high levels of mathematics proficiency. The school, teachers, and parents should be concerned about improving the levels of learners' satisfaction with their lives in order to improve their results on math tests. They should choose native learners who were born in the same country of tests to take part in these tests. Also, when speaking to learners at home, they should use the same language in which the test is written. They should also encourage learners to reach the highest level of education, raise their educational ambitions, and provide necessary parental support for all learners. Schools, teachers, and parents should provide a comfortable atmosphere for learners and make them feel comfortable with their lives. Finally, they should urge learners to be disciplined in school and not be absent or skip lessons or days.

\section{REFERENCES}

Abdelfattah, F., \& Lam, J. (2018). Linking Homework to Achievement in Mathematics: An Examination of 8th Grade Arab Participation in TIMSS 2015, International Journal of Instruction, 11 (4), 607-624.

Akyüz, G. (2014). The effects of student and school factors on mathematics achievement in TIMSS 2011. Education and Science, 39 (172), 150-162.

Alatyan, A. I. (2018). Estimating Items Parameters and Accuracy According to Threeparameter logistic model during Outliers Treatment of Timss Scores Data, Association of Arab Universities, Journal for Education and Psychology, 16(2), 201-249.

Al-Bursan, I. S., \& Tiegazza, M. B. (2012). The Assessment Practices of Mathematics Teachers for the Saudi and the South Korean Samples in TIMSS 2007, Saudi Society for Educational and Psychological Sciences (Justin), 25-53.

Al-Sheikhi, H. S. (2012). A proposed strategy to improve the level of students' achievement in the Kingdom of Saudi Arabia in mathematics in TIMSS competitions, Journal of Studies in Educational Sciences, 39(1), Al-Manhal. https://platform.almanhal.com/Files/2/33999

Ally, N. (2011). The Promotion of Mathematical Proficiency in Grade 6 Mathematics Classes from the UMgungundlovu District in KwaZulu-Natal. Master Thesis. https://researchspace.ukzn.ac.za/handle/10413/5791.

Al-Menoufy, S. G., \& Al-Mutham, K. A. (2014). Developing mathematics proficiency, a new approach in school mathematics, The Fourth Conference on Teaching and Learning Mathematics in General Education Distinguished research and experience, the Saudi Mathematical Association, 1-32.

Alonso, R. F., Alvarez, J. S., \& Muñiz, J. (2016). Homework and performance in mathematics: The role of the teacher, the family and the student's background. Revista de Psicodidáctica, 21(1), 5-23.

Althauser, K. (2015). Job-embedded professional development: Its impact on teacher self-efficacy and student performance. Teacher Development Journal, 19(2), 210-225. 
Andon, A., Thompson, C. G., \& Becker, B. J. (2014). A quantitative synthesis of the immigrant achievement gap across OECD countries, Large-scale Assessments in Education, 1-20.

Awofala, A.O.A. (2017). Assessing senior secondary school students" mathematical proficiency as related to gender and performance in mathematics in Nigeria. International Journal of Research in Education and Science (IJRES), 3(2), 488-502.

Azina, I., \& Halimah, A. (2012). Student factors and mathematics achievement: Evidence from TIMSS 2007. Eurasia Journal of Mathematics, Science \& Technology Education, 8(3), 249-255.

Ball, D. L. (2003). Mathematical Proficiency for All Students: Toward a Strategic Research and Development Program in Mathematics Education, RAND Mathematics Study Panel. https://www.rand.org/content/dam/rand/pubs/monograph_reports/MR1643/MR1643.pre f.pdf

Bartell, T. G., Webel, C., Bowel, B., \& Dyson, N. (2012). Prospective teacher learning: Recognizing evidence of conceptual understanding. Journal of Mathematics Teacher Education, 16, 57-79.

Baye, A., \& Monseur, C. (2016). Gender differences in variability and extreme scores in an international context, Large-scale Assessments in Education, 1-16.

Betts, J., Zau, A., \& Rice, L. (2003). Determinants of student achievement: New evidence from San Diego. Public Policy Institute of California. https://www.ppic.org/content/pubs/report/R_803JBR.pdf

Blau, D., \& Currie, J. (2006). Preschool, day care, and after school care: Who's minding the kids? In Handbook of the Economics of Education, E. Hanushek \& F. Welch (Eds.), Handbook of the Economics of Education, 2, 1163-1278. https://www.nber.org/papers/w10670

Borghans, L., \& Schils, T. (2011). The leaning tower of PISA: the effect of test motivation on scores in the international student assessment. Paphos, Cyprus: Paper presented at the EALE annual conference. 22-24.

Brownell, W. A. (2007). The progressive nature of learning mathematics. The Mathematics Teacher-100 Years of Mathematics Teacher, 100, 26-34.

Burdett, N., \& Sturman, L. (2013). A Comparison of PISA and TIMSS against England's National Curriculum, National Foundation for Educational Research, The Mere, Upton Park, Slough, Berkshire SL1 2DQ, 1-18.

Cai, J. (2003). Investigating parental roles in students' learning of mathematics from a cross-national perspective. Mathematics Education Research Journal, 15(2), 87-106.

Caponera, E., \& Losito, B. (2016). Context factors and student achievement in the IEA studies: Evidence from TIMSS. Large-scale Assessments in Education, 4(12), 2-22. 
Cooper, H., Lindsay, J., \& Nye, B. (2000). Homework in the home: How student, family, and parenting-style differences relate to the homework process. Contemporary Education Psychology, 25(4), 464-487.

Cosgrove, J., \& Cartwright, F. (2014). Changes in achievement on PISA: the case of Ireland and implications for international assessment practice, Large-scale Assessments in Education, 1-17.

Dee, T. S. (2007). Teachers and the gender gaps in student achievement. Journal of Human Resources, 42(3), 528-554.

Dhlamini, Z. B., \& Luneta, K. (2016). Exploration of the Levels of Mathematical Proficiency Displayed by Grade 12 Learners in Responses to Matric Examinations, International Journal of Education and Science, 13(2), 231-246.

Dronkers, J., Levels, M., \& Heus, M. D. (2014). Migrant pupils' scientific performance: the influence of educational system features of origin and destination countries, Largescale Assessments in Education, 1-28.

Eklöf, H., Pavešič, B. J., \& Grønmo, L. S. (2014). A Cross-National Comparison of Reported Effort and Mathematics Performance in TIMSS Advanced, Applied Measurement in Education, 27(1), 31-45.

Gray, H., Lyth, A., McKenna, C., Stothard, S., Tymms, P., \& Copping, L. (2019). Sex differences in variability across nations in reading, mathematics and science: a meta-analytic extension of Baye and Monseur (2016), Large-scale Assessment Education, 1-29.

Goe, L. (2007). The link between teacher quality and student outcomes: A research synthesis. National Comprehensive Centre for Teacher Quality, ETS, 1-72.

Goldhaber, D., \& Brewer, D. (2000). Does teacher certification matter? High school teacher certification status and student achievement. Educational Evaluation and Policy Analysis, 22(2), 129-145.

Groves, S. (2012). Developing mathematical proficiency. Journal of Science and Mathematics, 3(2), 119-145.

Guven, U., \& Akcay, A. O. (2019). Trends of Homework in Mathematics: Comparative Research Based on TIMSS Study, International Journal of Instruction, 12(1), 13671382.

Haelermans, C., \& Ghysels, J. (2014). The Effect of an Individualized Online Practice Tool on Math Performance: Evidence from a Randomized Field Experiment1. https://pdfs.semanticscholar.org/b3b6/9c633de1bcc3afd90aa7230d83a63aa2b1a1.pdf?_ $\mathrm{ga}=2.232849942 .94628267 .1589398641-654876092.1589398641$.

Hole, A., Grønmo, L. S. \& Onstad, T. (2018). The dependence on mathematical theory in TIMSS, PISA, and TIMSS Advanced test items and its relation to student achievement, Large-scale Assessments in Education, 1-17. 
Hussain, S., Lindh, J., \& Shukur, G. (2006). The effect of LEGO Training on Pupils' School Performance in Mathematics, Problem Solving Ability and Attitude: Swedish Data. Educational Technology \& Society, 9(3), 182-194.

Ismail, N. A. (2008). Effects of teachers and schools on Mathematics achievement. Problems of Education in the 21st Century, 6, 103-112.

Jeynes, W. H. (2005). A Meta-Analysis of the Relation of Parental Involvement to Urban Elementary School Student Academic Achievement, Urban Education, 40(3), 237-269.

Khedr, A. U \& Desouki S. A., (2014). The effect of a mathematics training program on the improvement of students' performance in training questions for international Pisa tests, Journal of the Faculty of Education, Port Said University, 15, 62-89.

Kilpatrick, J., Swafford, J., Findell, B. (2001). Adding It Up: Helping Children Learn Mathematics. Washington D.C: National Academy Press. https://www.nap.edu/catalog/9822/adding-it-up-helping-children-learn-mathematics

King, A. R. (2000). Relationships between CATI personality disorder variables and measures of academic performance. Personality and Individual Differences, 29(1), 177190.

Kodippili, A., (2011) "Parents' Education Level in Students' Mathematics Achievement; Do School Factors Matter?," Academic Leadership: The Online Journal: 9(1), Article 39. https://scholars.fhsu.edu/alj/vol9/iss1/39/

Koponen, T., Aunola, K., Ahonen, T., \& Nurmi, J. (2007). Cognitive predictors of single-digit and procedural calculation skills and their covariation with reading skill. Journal of Experimental Child Psychology, 97(3), 220-241.

Kovas, Y., Giampietro, V., Viding, E., Ng, V., Brammer, M., Barker, G. J., Francesca G. E. Happé, F. G. E., \& Plomin, R., (2009). Brain correlates of non-symbolic numerosity estimation in low and high mathematical ability children. PloS One, 4(2), https://journals.plos.org/plosone/article?id=10.1371/journal.pone.0004587.

Lameva, B., \& Chonteva, Z. (2013). A Cross-ethnic comparison of mathematics achievement in the trends in international mathematics and science study 2011 (Timss), International Association for the Evaluation of Educational Achievement, 1-11. https://www.iea.nl/publications/presentations/cross-ethnic-comparison mathematicsachievement-trends-international

MacGregor, D. (2013). The Academy of Math, Developing Mathematical Proficiency, Research-Based Math Intervention, EPS literacy and intervention, 1-9.

Maharaj, A., Brijlall, D., \& Narain, O. K. (2015). Improving proficiency in mathematics through website-based tasks: A case of basic algebra. International Journal of Educational Sciences, 8 (2), 369-386. 
Mammadove, R., \& Cimen, I. (2019). Optimizing Teacher Quality Based on Student Performance: A Data Envelopment Analysis on PISA and TALIS, International Journal of Instruction, 12(4), 767-788

Mikk, J. (2006). Students' homework and TIMSS 2003 mathematics results. Paper presented at the International Conference "Teaching Mathematics: Retrospective and Perspectives," Tartu, Estonia.

Mullis, I.V.S., Martin, M.O., Foy, P., \& Arora, A., (2012). TIMSS 2011 International Results in Mathematics. TIMSS \& PIRLS International Study Center, Lynch School of Education, Boston College Chestnut Hill, MA, USA. https://timssandpirls.bc.edu/timss2011/international-results-mathematics.html.

National Research Council (NRC), (2001). Adding It Up: Helping Children Learn Mathematics. Washington, DC: The National Academies Press. https://doi.org/10.17226/9822.

Odiembo, E. J. A., \& Simatwa, E. M. W. (2014). The relationship between secondary school mathematics teachers' age, gender, and students' academic achievement in mathematics in Kenya: A case study of Muhoroni sub county. Educational Research, 5(7), 225-240.

Organization for Economic Co-operation and Development (2019). PISA 2018 Results (Volume II), where all students can succeed, PISA, OECD Publishing, Paris. https://doi.org/10.1787/b5fd1b8f-en.

Penk, C., Pöhlmann, C., \& Roppelt, A. (2014). The role of test-taking motivation for students' performance in low-stakes assessments: an investigation of school-trackspecific differences, Large-scale Assessments in Education, 1-17.

Pivovarova, M., \& Powers, J. M. (2019). Generational status, immigrant concentration and academic achievement: comparing first and second-generation immigrants with third-plus generation students, Large-scale Assess Education journal, 1-18. file://C:/Users/Dr.Refat\%20Kandeel/Downloads/s40536-019-0075-4.pdf

Qwaider, O. Q., \& Al-Sawalmeh, Y. M. (2016). Outlier values in the performance of Jordanian students on the TIMSS test in mathematics and science and the effect of its treatment method on the results of statistical analyzes, Al-Quds Open University, AlManhal, 18-33. http://search.shamaa.org/FullRecord?ID=123242

Roby, D. E. (2004). Research on school attendance and student achievement: A study of Ohio schools. Educational Research Quarterly, 28(1), 3-16.

Scherer, R., \& Jens, F. B. (2014). The acquisition of problem solving competence: evidence from 41 countries that math and science education matters, Large-scale Assessments in Education, 2(10), 1-22.

Schoenfeld, A. H. (2007). What is Mathematical Proficiency and How Can It Be Assessed? Ch.5, Assessing Mathematical Proficiency, MSRI Publications, 53, 59-73. 
Schweinhart, L. J., Montie, J., Xiang, Z., Barnett, W. S., Belfield, C. R., \& Nores, M. (2005). Lifetime effects: The High/Scope Perry Preschool Study through age 40. Monographs of the High/Scope Educational Research Foundation, 14.

Shannag, Q. A., Tairab, H., Dodeen, H., \& Abdel-Fattah, F. (2013). Linking teachers' quality and student achievement in the kingdom of Saudi Arabia and Singapore: The impact of teachers' background variables on student achievement. Journal of Baltic Science Education, 12(5), 652-665.

Sirin, S. R. (2005). Socioeconomic status and academic achievement: A meta-analytic review of research. Review of Educational Research, 75(3), 417-453.

Skouras, A. (2012). Factors associated with middle-school mathematics achievement in Greece: The case of algebra. International Journal of Mathematical Education in Science and Technology, 45(1), 12-34.

Suh, J. M. (2007). Typing It All Together: Classroom Practices That Promote Mathematical proficiency for All Students. Teaching Children Mathematics. http://mason.gmu.edu/ jsuh4/tenure/part4thru8/papers/Tying_It_All_Together.pdf.

Thien, L. M., I. Darmawan, G. N., \& Ong, M. Y. (2015). Affective characteristics and mathematics performance in Indonesia, Malaysia, and Thailand: what can PISA 2012 data tell us? Large-scale Assessments in Education, 1-16.

Tucker-Drob, E. M., \& Harden, K. P. (2012). Early childhood cognitive development and parental cognitive stimulation: Evidence for reciprocal gene-environment transactions. Developmental Science, 15(2), 250-259.

Wayne, A. J., \& Youngs, P. (2003). Teacher characteristics and student achievement gain: A review. Review of Educational Research, 73(1), 89-122.

Wilder, S., (2014). Effects of parental involvement on academic achievement: A metasynthesis. Educational Review, 66(3), 377-397.

Wu, Q., Debeer, D., Buchholz, J., Hartig, J., \& Janssen, R. (2019). Predictors of individual performance changes related to item positions in PISA assessments, Largescale Assessments in Education, 1-21.

Zambak, V. S., Alston, D. M., Marshall, J. C., \& Tyminski, A. M. (2017). Convincing science teachers for inquiry-based instruction: Guskey's staff development model revisited. Science Educator, 25(2), 108-116. 